\title{
Breast Cancer Screening Practice and Associated Factors Among Women Aged 20-70 Years in Urban Settings of SNNPR, Ethiopia
}

This article was published in the following Dove Press journal: Breast Cancer: Targets and Therapy

\section{Abiyu Ayalew Assefa (D) Geleta Abera Medhin Geta}

Department of Public Health, Hawassa College of Health Science, Hawassa, Ethiopia
Correspondence: Abiyu Ayalew Assefa Department of Public Health, Hawassa College of Health Science, Hawassa, Ethiopia

Email abiyman143@gmail.com
Background: Breast cancer is the leading cause of morbidity and mortality among women in many countries around the globe. Early detection of breast cancer plays a great role in cancer prevention and treatment by potentially decreasing mortality. However, evidence is sparse on breast cancer screening practice among women in southern Ethiopia. Therefore, the aim of this study was to assess breast cancer screening practice and associated factors among women 20-70 years of age in an urban setting in SNNPR, Ethiopia.

Methods: A community-based cross-sectional study was conducted from March to April 2020. Multistage sampling technique was applied to select the study participants. Data were collected by using a pretested interviewer-administered structured questionnaire. Bivariable and multivariable logistic regression was done to confirm association between dependent variable and covariates.

Results: From the total study participants, 83 (13.6\%; 95\%CI: 10.8, 16.4\%), have regularly engaged in at least one breast cancer screening method. Women with a favorable attitude towards breast cancer and its screening $(\mathrm{AOR}=3.0 ; 95 \% \mathrm{CI}$ : $1.63-5.56)$, educational status of college and above $(\mathrm{AOR}=3.8 ; 95 \% \mathrm{CI}$ : 1.25- 11.48), family history of breast cancer $(\mathrm{AOR}=3.7$; 95\%CI: 1.73-7.96), awareness about breast cancer screening methods $(\mathrm{AOR}=3.0 ; 95 \% \mathrm{CI}: 1.46-6.22)$, knowing someone screened for breast cancer $(\mathrm{AOR}=2.2$; 95\% $\mathrm{CI}: 1.10-4.38$ ), and recommendation by health professionals for $\mathrm{BCS}$ (AOR=5.0; 95\% CI: $2.35-10.68)$ were variables significantly associated with BCS practice.

Conclusion: Breast cancer screening practice is low. Women with college and above education level, favorable attitude towards breast cancer and its screening, awareness about breast cancer screening methods, family history of breast cancer, having a recommendation from health professionals and knowing someone who screened for breast cancer were associated with BCS practice. Therefore, this finding implies the need to intervene upon those factors.

Keywords: breast cancer, breast cancer screening, cancer, Ethiopia, women aged 20-70 years

\section{Background}

Breast cancer (BC) is the leading cause of morbidity and mortality among women in many countries around the globe. ${ }^{1,2}$ In 2018, more than two million new cases of breast cancer were diagnosed which accounts for $25 \%$ of all cancers in women and $11.6 \%$ of all cancer types with the total death of 620,700 cases. Most of the deaths occurred in low and middle-income countries (LMICs). ${ }^{3}$

In LMICs BC accounts $27.3 \%$ of all cancers in women with an age-standardized incidence rate of 31.3 per $100,000 .^{4}$ In 2015 , BC was the most prevalent cancer in 
Ethiopia among the entire adult population $(30.2 \%){ }^{5}$ In 2018, breast cancer incidences of 15,244 (22.6\%) of all cancers among men and women were diagnosed in Ethiopia and it accounted for $32.9 \%$ of all diagnosed women's cancers diagnosed. In all, the most common adult cancers were cancers of the breast and cervix. ${ }^{6}$ The fourth and fifth decades were the peak age of incidence. Most were at the late stage of disease at their diagnosis. ${ }^{7}$

For decades LMICs have invested in early detection programs for breast and cervical cancer through screening, community education, and opportunistic case detection by health professionals. The effectiveness is inadequate due to low coverage, insufficient laboratory capacities for diagnosis, fragile health information system barriers that hinder women's utilization of services, and inadequate treatment options. ${ }^{4}$

Early detection of breast cancer plays a great role in cancer prevention and treatment by potentially decreasing mortality. ${ }^{2,8}$ Population-based mammography screening is associated with a mortality reduction of at least $30 \%$ and a $40 \%$ lower risk of advanced disease. The women who attended an organized mammography screening increased the five-year relative survival rate up to $90 \%{ }^{9}$

In developing countries with very limited health system capacity and lack of early-detection programs, the potential number of women with breast cancer are diagnosed in the late stages and the overall five-year survival rate is very low, with a range of $10-40 \% .^{10}$

Irrespective of the ongoing conflict points on the benefits and harms of BCS, various experts have belief in that the benefits of breast cancer screening outweigh the harm. ${ }^{11}$

The government of Ethiopia has recognized cancer as a major problem and has set a priority on the advancement of cancer care in the country. In 2015, the Ethiopian health-care authorities established a cancer control plan, which focussed on the prevention as well as the general improvement of cancer care in the country. There is a shortage of evidence on the effect of breast cancer screening methods in countries in which the population has limited breast cancer awareness where women typically present with late-stage breast cancer. ${ }^{5}$

Despite the fact that the Southern Nations Nationalities and People's Region (SNNPR) is among the top four regions in Ethiopia affected by breast cancer, ${ }^{7}$ local data on breast cancer incidence as well as its detection is lacking. Most studies conducted in Ethiopia focus on single detection methods lacking information on overall
BCS practice. Therefore, the aim of this study was to measure breast cancer screening practice and associated factors among women of 20-70 years living in the study area.

\section{Methods}

\section{Study Design and Setting}

A community-based cross-sectional study was conducted among women aged 20-70 years in urban settings of the Southern Nations Nationalities and People's Region, Ethiopia, from March 1 to April 30, 2020. SNNPR is among nine regional states of Ethiopia. It consists of 18 zones and seven special woredas. The estimated population of the SNNPR, based on the projection of plan and development office of SNNPR Regional Health Bureau was 20,551,606, of whom 10,481,319 are females. The estimated numbers of females in the age range of 20 to 70 years in 18 identified urban areas in SNNPR were 500,627 (SNNPR health bureau, plan and develpoment core process, 2020).

According to the SNNPR Regional Health Bureau report, there were six teaching referral hospitals, 12 general hospitals, 78 primary hospitals, 734 health centers, 3955 health posts, and 1704 private clinics providing services to the community (SNNPR health bureau, plan and development core process, 2020).In this region, there is one comprehensive cancer care and treatment center in Hawassa while other general hospitals provide breast cancer diagnosis and treatment as a unit in their perspective catchment. In addition, there are three health facilities providing mammography screening in the region. Therefore, cities having general hospital and above health facilities were eligible for this study.

\section{Source and Study Population}

All women aged 20-70 years who reside in urban settings of SNNPR were the source population, and systematically selected households with eligible women, who resided in the selected kebeles and consented to participate in the study were the study population.

\section{Sample Size and Sampling Techniques}

The sample size was determined using Epi Info version 7.1.4.0 by considering the following assumptions: the population proportion with the practice of breast cancer screening would be $50 \%$ (no previous similar study), $5 \%$ margin of error, a $95 \%$ confidence level. After considering a design effect of $1.5 \%$ due to the multistage sampling of 
study participants and a $10 \%$ increment for nonresponse, the sample size was determined to be 634 .

A multistage random sampling technique was used to select the study participants. All 18 zonal cities of the SNNPR will be included in the study. Six cities will be selected randomly. The six cities selected randomly were Hawassa, Halaba, Arba Minch, Tercha and Mizan Aman and Wolkite. The calculated sample size was proportionally allocated to each of the randomly selected cities, subcities, and kebeles. Households in each kebele were selected by employing a systematic random sampling procedure. If there was more than one eligible woman in the selected household one of them was randomly selected as a study participant. For households in which the women are not found at home, but it is known that there are eligible women for the study, the interviewers revisit the household at a different time (Additional file 1).

\section{Data Collection Instrument and Procedure}

A structured questionnaire was used to collect relevant information from each study participant on sociodemographic and economic factors, awareness of women on breast cancer, awareness of women on BCS methods, attitude towards BC and its screening practice, and other factors. The questionnaire was prepared by reviewing relevant literature ${ }^{10,12-17}$ with modification in line with the objectives of this particular study.

Primary data was collected using intervieweradministered questionnaires from eligible women. Ten female nurses were recruited as data collectors and six health officers were recruited as supervisors.

\section{Data Quality Assurance Methods}

The questionnaire was initially developed in English and later translated into Amharic by language experts. Two days of training was given to data collectors and supervisors on the aim of the study, the content of the questionnaire, and how to conduct the interview. The questionnaire was pretested on $5 \%$ of the total sample size in Yirgalem town, Ethiopia. Close supervision was taken during data collection by supervisors. The collected data were entered into EpiData software version 3.1.

\section{Data Processing and Analysis Methods}

All questionnaires were coded, cleaned, and entered into EpiData version 3.1 and exported to SPSS version 23 statistical software for analysis. Descriptive statistics results were compiled and presented using tables and graphs. The data was analyzed using logistic regression to determine the association of various factors on the outcome variable and to control confounding. First, the variables were fitted to the bivariate analysis. Then all variables having a $p$-value $<0.25$ in the bivariate analysis were entered into a multivariable logistic regression model for further analysis. ${ }^{18}$ Crude and adjusted odds ratios with their $95 \%$ confidence intervals were calculated. The multivariable model was tested for goodness of fit with the Hosmer-Lemeshow test and it is nonsignificant. Variables having $p$-value $<0.05$ in the multivariable analysis were taken as significantly associated.

Participants were asked "when was the last time you had screened for BC?" This question was designed based on screening recommendations from WHO. ${ }^{17}$ Participants who had undergone BSE every month regularly after menses or had examined by health professionals with in the last two years, or a mammography within the last one year were considered as having undergone breast cancer screening.

Awareness of breast cancer was measured by using 10 different questions. For each correct or positive answer, a score of " 1 " was given while " 0 " was given for every wrong or negative answer. A mean score was calculated for each participant, then individual above or equal to the mean score was considered as having good awareness about breast cancer whereas less than the mean score was considered as having poor awareness about BC. ${ }^{13}$

Awareness about BCS methods was measured in the following ways. If the woman mentioned at least one of the BCS methods (BSE, CBE, mammography, breast ultrasound, and biopsy) then she was considered as having awareness about BCS methods and if she did not mention any of the methods, then she was considered as not having awareness of BCS methods. ${ }^{13}$

The attitude of the women towards BC and its screening was assessed through eight different questions with five-points Likert scale response options ( $1=$ strongly disagree, $2=$ disagree, $3=$ neutral, $4=$ agree, $5=$ strongly agree). Negatively stated items (3, 4, and 5) were reverse coded for analysis. The reverse coding was done in the following way $(5=$ strongly disagree, $4=$ disagree, $3=$ neutral, $2=$ agree, $1=$ strongly agree). After calculating the mean score for each individual, individuals above or equal to the mean score were considered as having a favorable attitude towards $\mathrm{BC}$ and its screening whereas the score below 
the mean score was considered as an unfavorable attitude towards BC and its screening. ${ }^{13}$

\section{Results}

\section{Sociodemographic Characteristics of the Study Participants}

A total of 610 participants (aged 20-70 years) were interviewed with a response rate of $96.2 \%$. Most of the participants 340 (55.7\%) were within the age group of 20-34 years, with the mean $( \pm \mathrm{SD})$ age of $34.65( \pm 10.92)$ years. The majority of the participants 240 (39.3\%) were Orthodox by their religion and the majority of participants 478 (78.4\%) were ever married. Regarding educational status, participants having college and above educational status accounted for 222 (36.4\%) while 175 (28.7\%) had a primary and below schooling. Concerning the average monthly income of the households, 204 (33.4\%) of households earned between 2501 and 5000 ETB and 156 (25.6\%) earned more than 7501 ETB (Table 1).

\section{Awareness About Breast Cancer}

The mean score of participants' awareness about breast cancer was computed and used as a cutoff point for classifying awareness about BC as good or poor. Accordingly, the mean awareness score was $6.5 \pm 2.0 \mathrm{SD}$. More than half of participants $436(71.5 \%)$ had good awareness about BC (Table 1).

\section{Awareness About Breast Cancer Screening Methods}

An assessment of the participant's awareness of screening methods revealed that $225(36.9 \%)$, of participants mentioned at least one breast cancer screening method. The commonly mentioned breast screening techniques were: breast self-examination 152 (67.6\%), clinical breast examination 154 (68.4\%), mammography $54(24.0 \%)$ and ultrasound 10 (4.4) (Table 1).

\section{Attitude Towards Breast Cancer and Breast Cancer Screening}

The attitude mean score of the participants was computed and used as a cutoff point for classifying attitude towards BSE as favorable or not. Accordingly, the mean attitude score was 21.4 \pm 3.2 SD. More than one-third of participants 259 (42.5\%) had a favorable attitude toward breast cancer screening.
Table I Sociodemographic and Awareness, Attitude Towards BC and Its Screening Characteristics Among Women Aged 20-70 Years in Urban Setting of SNNPR Ethiopia, 2020

\begin{tabular}{|c|c|c|c|}
\hline Variables & Category & $\begin{array}{l}\text { Frequency } \\
\text { (n) }\end{array}$ & Percentage \\
\hline \multirow{3}{*}{$\begin{array}{l}\text { Age of respondents } \\
\text { (in years) }\end{array}$} & $20-34$ & 340 & 55.7 \\
\hline & $35-49$ & 196 & 32.1 \\
\hline & $50-70$ & 74 & 12.1 \\
\hline \multirow[t]{3}{*}{ Educational level } & $\begin{array}{l}\text { Primary and } \\
\text { below }\end{array}$ & 175 & 28.7 \\
\hline & $\begin{array}{l}\text { Secondary } \\
\text { school }\end{array}$ & 213 & 34.9 \\
\hline & $\begin{array}{l}\text { College and } \\
\text { above }\end{array}$ & 222 & 36.4 \\
\hline \multirow[t]{2}{*}{ Marital status } & Never married & 132 & 21.6 \\
\hline & Ever married & 478 & 78.4 \\
\hline \multirow{4}{*}{$\begin{array}{l}\text { Woman's } \\
\text { occupational status }\end{array}$} & Unemployed & 116 & 19.0 \\
\hline & Self-employed & $14 \mid$ & 23.1 \\
\hline & Housewife & 165 & 27.0 \\
\hline & $\begin{array}{l}\text { GOVI } \\
\text { NGO_employed }\end{array}$ & 188 & 30.8 \\
\hline \multirow[t]{3}{*}{$\begin{array}{l}\text { Husband's } \\
\text { educational status }\end{array}$} & $\begin{array}{l}\text { Primary and } \\
\text { below school }\end{array}$ & 75 & 12.3 \\
\hline & $\begin{array}{l}\text { Secondary } \\
\text { school }\end{array}$ & 87 & 14.3 \\
\hline & $\begin{array}{l}\text { College and } \\
\text { above }\end{array}$ & 252 & 41.3 \\
\hline \multirow{3}{*}{$\begin{array}{l}\text { Husband's } \\
\text { occupational status }\end{array}$} & Unemployed & 27 & 6.5 \\
\hline & Self-employed & 179 & 43.2 \\
\hline & $\begin{array}{l}\text { GOV/NGO } \\
\text { employed }\end{array}$ & 208 & 50.2 \\
\hline \multirow[t]{4}{*}{ Religion } & Catholic & 29 & 4.8 \\
\hline & Muslim & 100 & 16.4 \\
\hline & Orthodox & 240 & 39.3 \\
\hline & Protestant & 241 & 39.5 \\
\hline \multirow{4}{*}{$\begin{array}{l}\text { Average monthly } \\
\text { income (Ethiopian } \\
\text { birr) }\end{array}$} & $500 \mathrm{I}-7500$ & 97 & 15.9 \\
\hline & $\leq 2500$ & 153 & 25.1 \\
\hline & $\geq 750$ I & 156 & 25.6 \\
\hline & $250 I-5000$ & 204 & 33.4 \\
\hline
\end{tabular}


Table I (Continued).

\begin{tabular}{|l|l|l|l|}
\hline Variables & Category & $\begin{array}{l}\text { Frequency } \\
\text { (n) }\end{array}$ & Percentage \\
\hline Number of children & $\geq 5$ & 85 & 13.9 \\
\cline { 2 - 4 } & 0 & 150 & 24.6 \\
\cline { 2 - 4 } & $3-4$ & 171 & 28.0 \\
\cline { 2 - 4 } & $1-2$ & 204 & 33.4 \\
\hline Awareness about BC & Poor & 174 & 28.5 \\
\cline { 2 - 4 } & Good & 436 & 71.5 \\
\hline Awareness about & Yes & 225 & 36.9 \\
\cline { 2 - 4 } screening method & No & 385 & 63.1 \\
\hline Attitude towards BC & Favorable & 259 & 42.5 \\
\cline { 2 - 4 } and its screening & Unfavorable & 351 & 57.5 \\
\hline
\end{tabular}

Note: Unemployed (daily labor, student).

Among those who had favorable attitude, only 60 (23.17\%) practiced breast cancer screening regularly (Table 1 ).

\section{Personal and Family History of Breast Cancer}

Of the total study participants, only $52(8.5 \%)$ of them mentioned that they had family history of BC. Among women with family history of $\mathrm{BC}$, the affected family members were: aunt 21 (40.4\%), sister 17 (32.7\%), grandmother $9(17.3 \%)$, and mother $6(11.5 \%)$. Our finding also revealed that the proportion of women who had reported they have a personal history of breast cancer was $13(2.1 \%)$. Of all participants, 206 (33.8\%) of women mentioned that they know someone who screened for BC.

\section{Other Factors}

Out of the total participants, 320 (52.5\%) ever heard about breast cancer screening. The main source of information on breast cancer screening was a health professional 196 $(61.3 \%)$ followed by mass media 131 (40.9\%) (Figure 1$)$.

\section{Practice of Breast Cancer Screening}

From the total study participants, 127 (20.8\%) of them mentioned that they have ever engaged in at least one method of BCS. The proportion of women who had engaged in at least one of the breast cancer screening practice regularly is 83 $(13.6 \%)$ with $95 \% \mathrm{CI}(10.8,16.4 \%)$. In contrast, the methodspecific practice of participants' engagement to BSE, CBE,

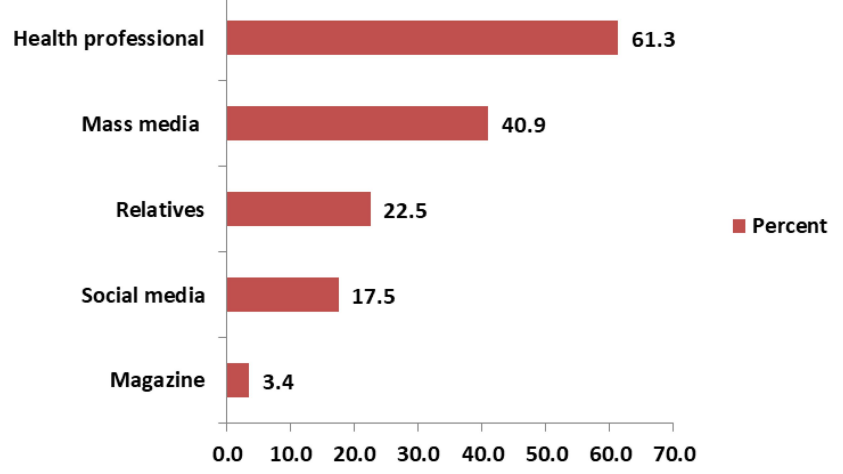

Figure I Source of information about BCS among women aged 20-70 years in urban setting of SNNPR, Ethiopia, 2020.

and mammography was $44(7.2 \%), 37(6.1 \%)$, and nine $(1.5 \%)$ respectively (Figure 2 ). The proportion of women who had practiced regularly at least one of breast cancer screening methods according to their ages 20-34 years, $35-49$ years and $50-70$ years were $42(51.8 \%), 33(39.8 \%)$ and $8(9.6 \%)$ respectively.

\section{Reason for Not Being Involved in BCS Practice}

The study finding indicated that more than three quarters $527(86.4 \%)$ of study participants were not undergoing the practice of BCS. The common reasons for not undergoing BCS were the absence of signs and symptoms of $\mathrm{BC}$ followed by a lack of knowledge about screening methods. Other less commonly mentioned reasons include negligence, fear of the result, and forgetfulness (Figure 3).

\section{Factors Associated with Practice of Breast Cancer Screening}

Bivariable logistic regression analysis was done to identify variables that met the criterion to be included in

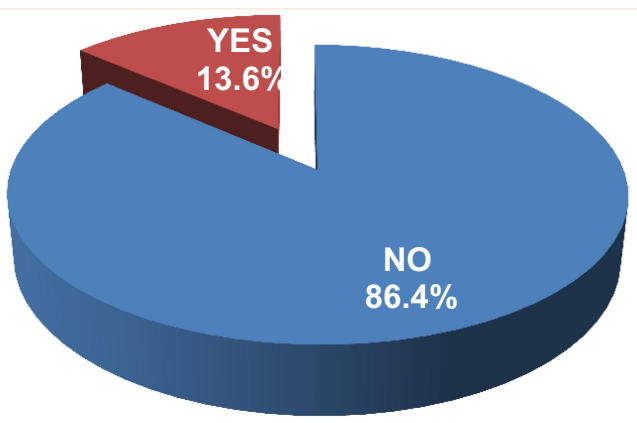

Figure 2 Regular breast cancer screening practice among women aged 20-70 years in urban setting of SNNPR, Ethiopia, 2020. 


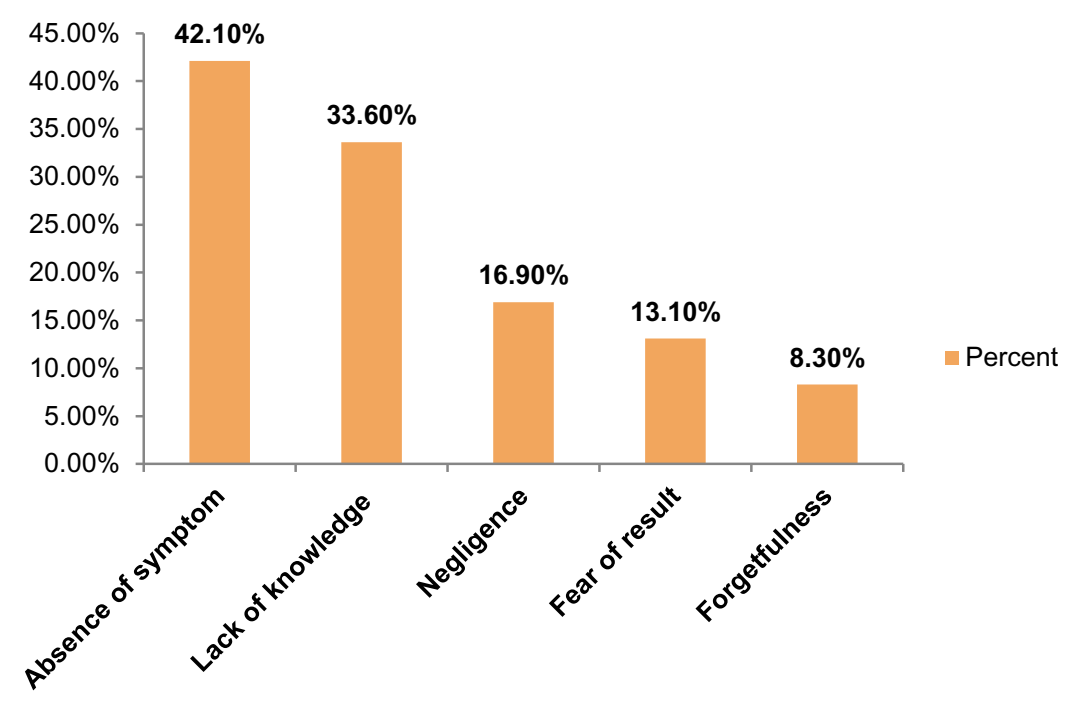

Figure 3 Reasons for not being involved in practice of BCS among women aged 20-70 years in urban setting of SNNPR, Ethiopia, 2020.

multivariable logistic regression. Accordingly, 11 variables namely, age of respondent, attitude towards breast cancer and its screening, women's educational status, women's occupational status, number of children, marital status, family history of breast cancer, awareness about breast cancer, awareness about breast cancer screening methods, knowing someone screened for breast cancer, and recommendation by health professionals showed significant association with BCS practice (Table 2).

For the final adjusted model, all candidate variables from the bivariable logistic regression analysis having a $p$-value of $<0.25$ were entered into a multivariable logistic regression model to control the confounding effect among the variables. Accordingly, women with favorable attitude towards breast cancer and its screening ( $\mathrm{AOR}=3.0 ; 95 \% \mathrm{CI}: 1.63-5.56)$, educational status of college and above $(\mathrm{AOR}=3.8 ; 95 \% \mathrm{CI}$ : $1.25-11.48)$, family history of breast cancer $(\mathrm{AOR}=3.7 ; 95 \%$ CI: 1.73-7.96), awareness about breast cancer screening methods (AOR=3.0; 95\%CI: 1.46-6.22), knowing someone screened for breast cancer ( $\mathrm{AOR}=2.2$; 95\%CI: $1.10-4.38$ ), and recommendation by health professionals for BCS ( $\mathrm{AOR}=5.0$; 95\%CI: 2.35-10.68)] were the variables significantly associated with BCS practice (Table 2).

\section{Discussion}

The primary aim of this community-based cross-sectional study was to measure the magnitude of breast cancer screening practice and associated factors among women aged 20-70 years in the urban setting of SNNPR, Ethiopia. The prevalence of breast cancer screening practice among women aged 20-70 years was very low. This study also found variables that are significantly associated with breast cancer screening practices like women's educational level, attitude towards breast cancer and its screening, awareness about breast cancer screening methods, family history of breast cancer, a recommendation from health professionals, and knowing someone who screened for breast cancer.

In this study, $13.6 \%$ of women regularly practiced breast cancer screening. This is in line with a study finding in Tunisia ${ }^{19}$ where $14.3 \%$ of women engaged in the proper practice of breast cancer screening. Whereas this finding is significantly higher than a study conducted in Kersa District, Eastern Ethiopia (6.9\%). ${ }^{12}$ This may be due to demographic differences as Kersa is a rural district.

In contrast, BCS practice is much lower than studies in Brazil $(62.3 \%),{ }^{20}$ Korea $(30.4 \%) .{ }^{21}$ It is also lower when compared with the finding of Addis Ababa (35.7\%). ${ }^{13}$ This discrepancy may be due to differences in socioeconomic differences, health accessibility, health system strength, and study setting differences.

In this study proportion of women who engaged in breast self-examination, clinical breast examination, and mammography as breast cancer screening method is $7.2 \%$, $6.1 \%$, and $1.5 \%$ respectively. This finding is much lower than a study finding of BCS among Arab women in the United Arab Emirates ${ }^{22}$ of $14.9 \%$ and $22 \%$ for CBE plus mammography and mammography alone, respectively.

Whereas the other systemic reviews conducted on studies assessing breast cancer early detection in sub-Saharan Africa $^{23}$ indicated that lifetime prevalence of BSE ranged from 5\% among women in Zambia to $89.2 \%$ among 
Table 2 Bivariable and Multivariable Logistic Regression of Variables Associated with Practice of BCS Among Women Aged 20-70 Years Old in SNNPR, Ethiopia, 2020

\begin{tabular}{|c|c|c|c|c|}
\hline \multirow[t]{2}{*}{ Variables } & \multicolumn{2}{|c|}{ Practice of BCS } & \multirow[t]{2}{*}{ COR $(95 \% \mathrm{Cl})$} & \multirow[t]{2}{*}{ AOR $(95 \% \mathrm{Cl})$} \\
\hline & Yes & No & & \\
\hline \multicolumn{5}{|l|}{ Age (years) } \\
\hline $20-34$ & 42 & 298 & I & I \\
\hline $35-49$ & 33 & 163 & $1.4(0.88-2.36)^{*}$ & $1.4(0.65-3.10)$ \\
\hline $50-70$ & 8 & 66 & $0.9(0.39-1.92)$ & $0.9(0.30-3.15)$ \\
\hline \multicolumn{5}{|c|}{ Woman's educational status } \\
\hline Illiterate/primary & 7 & 168 & I & I \\
\hline Secondary & 26 & 187 & $3.3(1.4 \mathrm{I}-7.89)^{*}$ & $2.0(0.69-5.80)$ \\
\hline College and above & 50 & 172 & $7.0(3.08-15.83)^{*}$ & $3.6(1.17-10.84)^{* *}$ \\
\hline \multicolumn{5}{|c|}{ Woman's occupational status } \\
\hline Unemployed & 13 & 107 & 1 & I \\
\hline Gov/NGO-employed & 41 & 147 & $2.3(1.17-4.49)^{*}$ & $0.5(0.21-1.35)$ \\
\hline Self-employed & 16 & 123 & I.I (0.49-2.33) & $0.5(0.18-1.35)$ \\
\hline Housewife & 13 & 150 & $0.7(0.32-1.60)$ & $0.9(0.30-3.00)$ \\
\hline \multicolumn{5}{|l|}{ Marital status } \\
\hline Ever married & 70 & 408 & $1.6(0.84-2.94)^{*}$ & I.I (0.17-6.79) \\
\hline Never married & 13 & 119 & I & I \\
\hline \multicolumn{5}{|l|}{ Number of children } \\
\hline 0 & 15 & 135 & I & I \\
\hline $\mathrm{I}-2$ & 26 & 178 & $1.3(0.67-2.58)$ & $2.1(0.34-13.49)$ \\
\hline $3-4$ & 27 & 144 & $\mathrm{I} .7(0.86-3.3 \mathrm{I})^{*}$ & $2.0(0.29-14.15)$ \\
\hline$\geq 5$ & 15 & 135 & $1.9(0.89-4.17)^{*}$ & $3.4(0.44-26.10)$ \\
\hline \multicolumn{5}{|l|}{ Family history of BC } \\
\hline Yes & 25 & 27 & $8.0(4.35-14.66)^{*}$ & $3.9(I .8 I-8.4 I)^{* *}$ \\
\hline No & 58 & 500 & 1 & I \\
\hline \multicolumn{5}{|l|}{ Awareness about BC } \\
\hline Good & 71 & 365 & $2.6(1.39-4.98)^{*}$ & $0.8(0.37-1.82)$ \\
\hline Poor & 12 & 162 & I & I \\
\hline \multicolumn{5}{|c|}{ Awareness about BCS methods } \\
\hline Yes & 67 & 158 & $9.8(5.50-17.40)^{*}$ & $3.0(1.46-6.22)^{* *}$ \\
\hline No & 16 & 369 & 1 & I \\
\hline \multicolumn{5}{|c|}{ Knowing someone screened for BC } \\
\hline Yes & 64 & 142 & $9.1(5.29-15.78)^{*}$ & $2.1(1.07-4.31)^{* *}$ \\
\hline
\end{tabular}


Table 2 (Continued).

\begin{tabular}{|c|c|c|c|c|}
\hline \multirow[t]{2}{*}{ Variables } & \multicolumn{2}{|c|}{ Practice of BCS } & \multirow[t]{2}{*}{ COR $(95 \% \mathrm{Cl})$} & \multirow[t]{2}{*}{ AOR $(95 \% \mathrm{Cl})$} \\
\hline & Yes & No & & \\
\hline No & 19 & 385 & I & I \\
\hline \multicolumn{5}{|c|}{ Attitude toward BC and its screening } \\
\hline Favorable & 60 & 199 & $4.3(2.58-7.17)^{*}$ & $3.0(1.65-5.63)^{* *}$ \\
\hline Unfavorable & 23 & 328 & I & I \\
\hline \multicolumn{5}{|c|}{ BCS recommendation by health professional } \\
\hline Yes & 71 & 159 & $13.7(7.23-25.96)^{*}$ & $5.0(2.35-10.68)^{* *}$ \\
\hline No & 12 & 368 & I & I \\
\hline
\end{tabular}

Notes: *Variables with a $p$-value of $\leq 0.25$, **significant at $p$-value $<0.05$, I: reference, unemployed (daily labor, student).

Abbreviations: COR, crude odds ratio; AOR, adjusted odds ratio.

female health workers in urban Nigeria. Similarly, mammography ranged from $1.6 \%$ in an urban population of Botswana to $7.8 \%$ among nurses working at a general hospital in Lagos, Nigeria, and $\mathrm{CBE}$ ranged from 2\% among rural women in Nigeria to $28.9 \%$ among nurses in Lagos, Nigeria. Although our finding lies in the range of findings from different studies, discrepancies may be due to the finding in this review that was reported as lifetime prevalence, in a segment of the population like nurses and difference in sociodemographic characteristics.

The method-specific prevalence findings in this study are much lower than the study conducted in Addis Ababa ${ }^{13}$ where $24.3 \%, 7.6 \%$, and $3.8 \%$ of respondents mentioned they are engaged in BSE, CBE, and mammography, respectively. This may be due to study setting differences.

The findings of our study suggest that educational level has a positive effect on BCS practice. Participants who had college and above education level were more likely to be screened for breast cancer compared to participants who had primary and below school education level. The same finding was observed in a study done in Iran, ${ }^{24}$ which supports this finding. Moreover, study finding from Addis $\mathrm{Ababa}^{13}$ and Mekelle ${ }^{25}$ showed that having a higher educational level is a predicting factor for a women's engagement in BCS practice. This is not surprising as we expect those women who are educated to have a good understanding of BC and its screening methods as well as the importance of early detection of BC. Furthermore, this finding is also supported by studies conducted in China, ${ }^{26}$ Arab women of Qatar, ${ }^{27}$ women in Muar district Malaysia, ${ }^{28}$ as well as an analysis of WHO studies ${ }^{29}$ showing higher educational level significantly improves screening rates in low-income and middle-income countries. This may be due to higher education being able to increase women's beliefs, knowledge on $\mathrm{BC}$, and health-seeking behavior.

Having a high level of awareness about breast cancer screening is important for the success of prevention and intervention. This is evidenced in our study that having awareness about breast cancer screening methods is one of the significantly associated factors of BCS practice. The women who had awareness about breast cancer screening methods were three times more likely to engage in one of the breast cancer screening practices compared to those who had no awareness about breast cancer screening methods. Our finding is comparable with another report that a lack of awareness about the early detection of BC among African women living in sub-Saharan Africa was one reason for the low uptake of BCS practice. ${ }^{30}$

In the present study women who have favorable attitudes were three times more likely to practice BCS than their counterparts. This is supported by the study conducted in China, ${ }^{31}$ Korea, $^{21}$ Iran. $^{24}$ This finding is also evidenced by studies done in Cameroon, ${ }^{32}$ Addis $\mathrm{Ababa}^{33}$ and Dire Dawa $^{34}$ that indicated that having a favorable attitude increases BSE practice. This could be explained by respondents with favorable attitude toward medical evaluation for early detection could have better motivation to practice breast cancer screening.

In this study family history of breast cancer was found to have a significant association with BCS practice. The odds of getting screened for breast cancer among women with a positive family history of $\mathrm{BC}$ is 3.9 times higher than those who have no family history of BC. Another similar report was found in another study conducted in Tunisia $^{19}$ and Addis Ababa. ${ }^{13}$ This may be a family 
history of breast illness perhaps gave them a chance to have information about BCS methods and increases health-seeking behavior.

In this study, it was found that breast cancer screening recommendation by health professionals is one of the significantly associated factors of the practice of BCS. The odds of getting screened among women who had a recommendation for BCS by health professionals were five times higher than those who had no recommendation for BCS by health professionals. This finding is consistent with studies done in Canada, ${ }^{35}$ Colombia, ${ }^{36}$ China $^{31}{ }^{31}$ UAE$^{22}$ and West Gojjam Zone, Northwest Ethiopia ${ }^{37}$ that having a recommendation on BCS from a health professional is a predictor of BCS practice. This might be due to providing a recommendation for breast cancer screening that can act as an opportunity to educate women about the importance of breast cancer screening which in turn helps the practice of BCS.

Finally, our study found that knowing someone who had screened for BC is significantly associated with BCS practice. Accordingly, knowing someone who had screened for BCS was twice as likely to be engaged in BCS practice compared to those who do not know someone who was screened. Despite the fact that, there is no study with similar findings to explain this association, the possible reason might be due to knowing someone may increase their awareness about BCS methods and importance of being screened.

\section{Conclusions}

This study has attempted to investigate and ascertain results from which this conclusion emerged. Generally, the BCS practice of women in the community level of the affluent towns in the region was low. The main reasons given by women for not undergoing screening were the absence of symptoms and lack of knowledge. Health-care providers were the main source of information about breast cancer and its screening.

College and above educational level, awareness about breast cancer screening methods, attitude toward breast cancer and its screening, family history of breast cancer, BCS recommendation by a health professional, and knowing someone screened for breast cancer were significantly associated factors with BCS practice.

\section{Abbreviations}

$\mathrm{AOR}$, adjusted odds ratio; $\mathrm{BC}$, breast cancer; $\mathrm{BCS}$, breast cancer screening; BSE, breast self-examination; CBE, clinical breast examination; COR, crude odds ratio; LMICs, low and middle-income countries.

\section{Data Sharing Statement}

Data is not available for online access, however readers who wish to gain access to the data can write to the corresponding author Abiyu Ayalew Assefa at abiyman143@gmail.com.

\section{Research Ethics and Consent}

All the ethical guidelines and principles placed in the Declaration of Helsinki and others, essential to address the ethical aspects of the research commenced in humans were taken into account. Accordingly, the proposal for the study was submitted to the Ethical Review Committee of Hawassa College of Health Science for approval and clearance and then the study was checked for its ethical issue and an official letter was attained (meeting on April 27, 2020 and ref. no. HCHS05/15/1052/1). Subsequently, the official letter granted from the HCHS citing the above ethical approval reference number was distributed to the respective Southern Nations Nationalities Regional health bureau and woreda health offices, including to all of the institutions selected to conduct the study. Data were collected unlinked anonymously, without any personal identifiers. All participants were informed about the aim of the study and enrolled entirely after written informed consent was obtained. Confidentiality was assured and participants were told they had the right to withdraw from the interview at any time they wanted.

\section{Acknowledgment}

We would like to express our deepest gratitude to research and community services core process of Hawassa College of Health Sciences for giving us this opportunity. SNNPR health bureau, we thank you for your unreserved support upon our research proposal work.

Finally, we would like to acknowledge Hawassa College of Health Sciences for funding this research paper.

The last but not the least our special thanks goes to Hawassa College of Health Sciences library staffs.

\section{Author Contributions}

All authors made substantial contributions to conception and design, acquisition of data, or analysis and interpretation of data; took part in drafting the article or revising it critically for important intellectual content; agreed to submit to the current 
journal; gave final approval of the version to be published; and agree to be accountable for all aspects of the work.

\section{Funding}

The study was funded by Hawassa College of Health Sciences. The funders had no role in study design, data collection, and analysis, decision to publish, or preparation of the manuscript. All these activities were accomplished through the determination of investigators as part of research service of the college. We would also like to inform you that we did not have a grant number.

\section{Disclosure}

The authors report no conflicts of interest in this work.

\section{References}

1. American Cancer Society. Breast Cancer Facts \& Figures 2019-2020. Atlanta: American Cancer Society, Inc; 2019.

2. WHO. Global Cancer Statistics. 2018.

3. American Cancer Society. Global Cancer Facts \& Figures. 4th ed. Atlanta: American Cancer Society; 2018.

4. Bray F, Ferlay J, Soerjomataram I, et al. Global cancer statistics 2018: GLOBOCAN estimates of incidence and mortality worldwide for 36 cancers in 185 countries. CA Cancer J Clin. 2018;68 (6):394-424. doi:10.3322/caac. 21492

5. Federal Ministry of Health Ethiopia. National Cancer Control Plan 2016-2020. 2015.

6. Ferlay J, Colombet M, Soerjomataram I. Estimating the global cancer incidence and mortality in 2018: GLOBOCAN sources and methods. Int J Cancer. 2019;144(8): 1941-1953. doi:10.1002/ijc.31937

7. Abate SM, Assefa YZ. Trends of breast cancer in Ethiopia. Int J Cancer Res Mol Mech. 2016;2(1).

8. Siegel RL, Miller KD, Jemal A. Cancer statistics, 2019. CA Cancer J Clin. 2019;69(1):7-34. doi:10.3322/caac.21551

9. Trimboli RM, Nicolò Matteo PGR, Battisti NML. Do we still need breast cancer screening in the era of targeted therapies and precision medicine? Insights Imaging. 2020;11(105). doi:10.1186/s13244-02000905-3

10. WHO. Position Paper on Mammography Screening Guidelines. 2014.

11. Meteb Al-Foheidi EMI. Breast cancer screening: review of benefits and harms, and recommendations for developing and low-income countries. Med Oncol. 2013;30(471).

12. Dibisa TM, Lemma Negesa TFG, Hawareya TG, Abate D, Abate D. Breast cancer screening practice and its associated factors among women in Kersa District, Eastern Ethiopia. Pan Afr Med J. 2019;33 (144). doi:10.11604/pamj.2019.33.144.18062

13. Abeje S, Seme A, Tibelt A. Factors associated with breast cancer screening awareness and practices of women in Addis Ababa, Ethiopia. BMC Women's Health. 2019;19(4). doi:10.1186/s12905018-0695-9

14. Wurjine TH, Zeleke Argaw NB, Bogale N. Assessment of knowledge, attitude and practice towards breast cancer early detection methods among female health professionals at public health centers of Addis Ababa, Ethiopia, 2017. MOJ Women's Health. 2019;8(3): 201-209. doi:10.15406/mojwh.2019.08.00237

15. Mzumara LAGBM. Breast cancer screening in low- and middle-income countries: a perspective from Malawi. Am Soc Clin Oncol. 2016;4(1).
16. Elobaid YE, Aw TC, Grivna M, Nagelkerke N. Breast cancer screening awareness, knowledge, and practice among arab women in the United Arab Emirates: a cross-sectional survey. PLoS One. 2014;9 (9):e105783. doi:10.1371/journal.pone. 0105783

17. WHO. Guidelines for the Early Detection and Screening of Breast Cancer, in EMRO Technical Publications Series 30. 2006.

18. Hosmer DW. Applied Logistic Regression Book. 2000.

19. Mhamdi SE, Amel Mhirsi IB, Sriha A, Salem KB, Soltani MS. Women's knowledge, attitudes and practice about breast cancer screening in the region of Monastir (Tunisia). Aust J Prim Health. 2012.

20. Buranello MC, Isabel Aparecida MCCCM, Walsh IAPD, Pereira GDA, Castro SSD. Breast cancer screening practice and associated factors: women's health survey in Uberaba MG Brazil, 2014. Cien Saude Cole. 2018;23(8):2661-2670. doi:10.1590/1413-81232018238.14762016

21. Kiheon Lee† HTL. Factors associated with use of breast cancer screening services by women aged $\geq 40$ years in Korea: the third Korea national health and nutrition examination survey 2005 (KNHANES III). BMC Cancer. 2010;10(144).

22. Ibrahim AO, Lujain SAS. Determinants of breast cancer screening practices: a survey of women in ajman, UAE. Proceedings of the 6th Annual Scientific Meeting of Gulf Medical University, 2014.

23. Richmond EB. Improving early detection of breast cancer in sub-Saharan Africa: why mammography may not be the way forward. Global Health. 2019;15(3).

24. Tilaki KH. Awareness, attitude, and practice of breast cancer screening women, and the associated socio-demographic characteristics, in Northern Iran. Iran J Cancer Prev. 2015;8(4).

25. Befikadu Legesse TG. Knowledge on breast cancer and its prevention among women household heads in Northern Ethiopia. Open J Prev Med. 2014;4(1).

26. Kim JI, Oh KO, Li CY, Min HS. Breast cancer screening practice and health-promoting behavior among chinese women. Asian Nurs Res (Korean Soc Nurs Sci). 2011;5:157-163.

27. Donnelly TT, Mohamed Ghaith A-HAK. Do socioeconomic factors influence breast cancer screening practices among Arab women in Qatar? BMJ Open. 2014;5.

28. Marzo RR, Vimalan Letchumanan DS, Anbarasu S, Ramiah TR. Breast cancer screening practice: early detection saves lives. Emerg Med. 2018;8(4).

29. Tomi Akinyemiju KO, Sakhuja S, Ogbhodo V, Braithwaite D, Braithwaite D. Life-course socioeconomic status and breast and cervical cancer screening: analysis of the WHO's study on global ageing and adult health (SAGE). BMJ Open. 2016;6:e12753. doi:10.1136/bmjopen-2016-012753

30. Akuoko CP, Theresa Sarpong EA, Quansah DY. Barriers to early presentation and diagnosis of breast cancer among African women living in sub-Saharan Africa. PLoS One. 2017;12(2):e0171024. doi:10.1371/journal.pone.0171024

31. Zijing W, Xiaohan YL. Factors associated with breast cancer screening participation among women in mainland China: a systematic review. BMJ Open. 2018.

32. Nde FP, Assob JCN, Kwenti TE, et al. Knowledge, attitude and practice of breast self-examination among female undergraduate students in the University of Buea. BMC Res Notes. 2015;8:43. doi:10.1186/s13104-015-1004-4

33. Getu MA. Assessment of breast self-examination practice and its associated factors among female undergraduate students in Addis Ababa University, Addis Ababa, Ethiopia, 2016. Breast Cancer (Dove Med Press). 2019;11:21-28.

34. Imam Dagne FT. Breast self-examination practice and associated factors among female healthcare professionals at Dire Dawa administration, Eastern Ethiopia. Eur J Biomed Pharm Sci. 2019;6(1).

35. Todd L, Hoffman-Goetz HE, Hoffman-Goetz L. Predicting breast and colon cancer screening among english-as-a second-language older chinese immigrant women to Canada. $J$ Cancer Educ. 2011;26:161-169. doi:10.1007/s13187-010-0141-7 
36. Torres JM, Natalia Quintero-Contreras CEP-R, Galván JS, LópezMayorga R, Rojas-Tinico Y, Ramírez-Vélez R. Barriers associated with breast self-examination among women 18 to 50 years old: a cross sectional study. Nutr Hosp. 2015;32:1664-1669.
37. Muluken Azage GA, Mekonnen A. Assessment of factors associated with breast self-examination among health extension workers in West Gojjam Zone, Northwest Ethiopia. Int J Breast Cancer. 2013.

\section{Publish your work in this journal}

Breast Cancer - Targets and Therapy is an international, peer-reviewed open access journal focusing on breast cancer research, identification of therapeutic targets and the optimal use of preventative and integrated treatment interventions to achieve improved outcomes, enhanced survival and quality of life for the cancer patient.
The manuscript management system is completely online and includes a very quick and fair peer-review system, which is all easy to use. Visit http://www.dovepress.com/testimonials.php to read real quotes from published authors. 